\title{
Contribution of animal foods to intakes of energy, fat, saturated fat in the Scottish Diet
}

This abstract was presented as the Public Health Nutrition Theme highlight.

As national and global food supplies are constantly evolving, it is important to assess the contribution of different food categories to overall food intake, energy, fat, and saturated fat, and consider their impact in terms of environmental sustainability. Recent work has shown that foods from animals contribute approximately two-thirds of greenhouse gas emissions from food and are also disproportionate when compared to the Eatwell plate guide to healthy eating ${ }^{(1)}$.

Household food purchase data from 2001 to 2012 combined, for Scotland, from the UK Living Costs and Food Survey (Expenditure and Food Survey until 2008) were analysed to estimate the contribution that selected food groupings made to intakes of energy, fat, saturated fat and overall weight of the diet. Adjustments were made for waste ${ }^{(2)}$ and data were analysed using general linear models within the complex samples module of SPSS (SPSS Inc., Chicago, IL, USA) weighting to the Scottish population and taking account of sampling methods. Results are provided for population data (i.e. includes consumers and non-consumers), in descending order by energy contribution. Figures are the amount and $\%$ contribution of each food grouping to the total intake in terms of energy, fat, saturated fat and overall weight of food, for selected food groupings that include animal products.

\begin{tabular}{|c|c|c|c|c|c|c|c|c|}
\hline \multirow[b]{2}{*}{ Food Grouping } & \multicolumn{2}{|l|}{ Energy } & \multicolumn{2}{|l|}{ Fat } & \multicolumn{2}{|c|}{ Saturated Fat } & \multicolumn{2}{|c|}{ Total weight } \\
\hline & $\overline{\mathrm{kJ} / \text { day }}$ & $\%$ & $\overline{g / d a y}$ & $\%$ & g/day & $\%$ & $\overline{g / d a y}$ & $\%$ \\
\hline Total processed red meat products & 643 & $7 \cdot 5$ & $10 \cdot 7$ & $12 \cdot 3$ & $4 \cdot 1$ & $12 \cdot 1$ & $63 \cdot 2$ & 3.8 \\
\hline Unprocessed red meat & 218 & $2 \cdot 5$ & $3 \cdot 4$ & $4 \cdot 0$ & 1.5 & $4 \cdot 3$ & $27 \cdot 4$ & $1 \cdot 6$ \\
\hline Total milk & 525 & $6 \cdot 1$ & $5 \cdot 6$ & $6 \cdot 4$ & $3 \cdot 5$ & $10 \cdot 3$ & 228 & $13 \cdot 7$ \\
\hline Total cheese & 220 & $2 \cdot 6$ & $4 \cdot 4$ & $5 \cdot 1$ & $2 \cdot 8$ & $8 \cdot 2$ & $14 \cdot 6$ & $0 \cdot 9$ \\
\hline Eggs & $75 \cdot 8$ & $0 \cdot 9$ & 1.4 & $1 \cdot 6$ & $0 \cdot 4$ & $1 \cdot 1$ & 1.0 & $0 \cdot 1$ \\
\hline Poultry & 159 & 1.8 & $2 \cdot 0$ & $2 \cdot 4$ & $0 \cdot 6$ & 1.7 & $29 \cdot 7$ & $1 \cdot 8$ \\
\hline Total weight of food & & & & & & & 1671 & \\
\hline
\end{tabular}

Processed red meat has not been disaggregated and may include starch component, eg potato, pastry, bread.

The results highlight that the largest contributor from animal based foods to energy, fat and saturated fat is processed red meat products, followed by milk. Processed red meat has been linked to colorectal cancer and the evidence-based WCRF report ${ }^{(4)}$ on cancer prevention advises that very little should be consumed. Reduction of processed red meat consumption has the potential to improve both health and sustainability. In contrast poultry products have been found to be amongst the most environmentally friendly animalbased food, especially when the GHG emissions are concerned. This is due to the high feed efficiency and minimal methane emissions compared to ruminant production.

Funded by the Food Standards Agency Scotland and Scottish Government Project no. FS4240180. Data provided by DEFRA, Scottish Neighborhood Statistics, ONS and the UK Data Archive.

1. MacDiarmid et al. (2011) Livewell: a balance of healthy and sustainable food choices. WWF UK - Livewell report 2011. London, http://assets.wwf. org.uk/downloads/livewell_report_corrected.pdf

2. Waste and Resource Action Programme (2007) The food we waste. Oxon: WRAP.

3. World Cancer Research Fund / American Institute for Cancer Research (2007) Food, nutrition, physical activity and the prevention of cancer: a global perspective. Washington, D.C., American Institute for Cancer Research. 